\title{
Research
}

\section{Fit for purpose? Using the fit note with patients with chronic pain:}

\author{
a qualitative study
}

\section{Abstract \\ Background \\ Staying in work may benefit patients with chronic pain, but can be difficult for GPs to negotiate with patients and their employers. The new fit note is designed to help this process, but little is known of how it is operating.}

\section{Aim}

To explore GPs' views on the fit note, with particular reference to sickness certification for patients with chronic pain.

\section{Design and setting}

Qualitative study using semi-structured interviews in eight primary care trusts in southwest England.

\section{Method}

In-depth interviews with $13 \mathrm{GPs}$

\section{Results}

GPs reported that the rationale behind the fit note is sound and that it may help patients with chronic pain to return to work earlier. However, GPs also reported barriers to successful fit note use, including the need to preserve doctor-patient relationships, inconsistent engagement from employers, GPs' lack of specialist occupational health knowledge, issues with fit note training, and whether a new form can achieve cultural shift.

\section{Conclusion}

While doctors agree that good work improves health outcomes, they do not think that fit notes will greatly alter sickness-certification rates without more concerted initiatives to manage the tripartite negotiation between doctor, patient, and employer.

\section{Keywords}

chronic disease; general practice; pain; sick leave.

\section{INTRODUCTION}

Sickness certification is one of the more potent healthcare interventions for common health problems. ${ }^{1}$ Certification is a key part of clinical management, allowing muchneeded recovery and repair, validating the patient as sick, ${ }^{2}$ and providing access to sickness benefits and rehabilitation However, sickness certification can also, paradoxically, promote disability, incapacity, stress, high resource use, and unwelcome prolongation of the sick role. ${ }^{1}$ Appropriate use of the sick note has, therefore, been a potential source of tension in the doctor-patient relationship, ${ }^{3-12}$ particularly for chronic pain, in which $75 \%$ of cases seen in general practice or in receipt of incapacity benefits can be classed as medically unexplained. ${ }^{13}$ As the diagnosis of chronic pain is essentially contestable, ${ }^{14-16}$ the determination of whether or not a patient can work can also be difficult to decide.

Rates of sickness absence in the UK have risen sharply since 1970, ${ }^{17}$ arguably for social as well as medical reasons. In Working for a Healthier Tomorrow, Black comments that British life expectancy is higher than ever before, and we have an excellent workplace health and safety record, yet 175 million working days were lost to sickness in 2006. She argues this reflects patterns of poverty and social exclusion'. ${ }^{17}$ There is also some evidence that sick note negotiations are influenced by normative expectations around what is an acceptable reason to be off work. ${ }^{18,19}$

Sickness certification can lead to long-

E Wainwright; MSc, doctoral researcher, Bath Centre for Pain Research. E Keogh; PhD, reader Deputy Director of the Bath Centre for Pain Research. C Eccleston, PhD, director of the Bath Centre for Pain Research. D Wainwright $\mathrm{PhD}$, senior lecturer in Health Services Research, Department for Health, University of Bath, Bath. Address for correspondence

Elaine Wainwright, Centre for Pain Research, term uptake of incapacity benefits, which is not only costly, but can also have disabling effects on the patient. ${ }^{13,17,20}$ The Labour government responded to high rates of sickness certification by rolling out a national educational programme for stakeholders, based on evidence that work, in which physical risk factors are controlled, is good for most people's health. ${ }^{21}$ The Coalition government elected in 2010 has continued with this. Because GPs are the gatekeepers to sick leave, they have been targeted as key agents of change in the reduction of sick-listing certification.

Fit notes (properly called the Statement of Fitness for Workl replaced sick notes, or Med 3s, in April 2010.22 They focus on capacity rather than incapacity, and are based on evidence that patient need not be $100 \%$ fit in order to work. The GP must either advise that the patient is not fit for work, or may be fit for work taking into account certain advice, including: a phased return to work; altered hours; amended duties; and/or workplace adaptations.

The Department for Work and Pensions (DWP) emailed an 18-page document to each practice, discussing why the fit note was introduced, and how to complete the new form, and suggested management of back-to-work issues within a consultation. ${ }^{23}$ The Royal College of General Practitioners (RGCP) offers half-day training on health, work, and wellbeing. The nominal fee may sometimes be waived.

There is little research on fit notes at present, particularly in relation to more

University of Bath, Bath, BA2 7AY

E-mail: esh26abath.ac.uk

Submitted: 13 April 2011; Editor's response: 12 May 2011; final acceptance: 20 June 2011. @British Journal of General Practice

This is the full-length article (published online 28 Nov 2011) of an abridged version published in print. Cite this article as: Br J Gen Pract 2011; DOI: 10.3399/bjgp11X613133 


\section{How this fits in}

Many doctors find sickness certification challenging, especially for conditions that rely more on patients' accounts than observable pathology, such as some chronic pain conditions. The fit note, introduced in April 2010, is meant to assist with return-to-work negotiations, but little is known of how it is operating. As part of a larger study, this study researched doctors' views on the fit note and how it impacts on sickness-certification consultations with patients with chronic pain.

subjective conditions, like chronic pain, which make sickness certification especially difficult to negotiate. ${ }^{24}$ Rates of sickness certification are high, for example, $23 \%$ of GP sick notes are issued for musculoskeletal disorders, ${ }^{13}$ yet there is little literature that specifically explores the views of GPs and patients with chronic pain on sickness certification.

There is an established body of evidence showing that GPs often experience difficulties with sick-listing negotiations. ${ }^{3-12}$ Studies have concluded that there is a need for more information about how and why sickness certification is problematic and how to improve the process. ${ }^{12,25,26}$ The primary goal of this study is to address this gap in knowledge, and gain an insight into how the new fit note might be used to improve sickness certification for the chronic pain patient.

\section{METHOD}

Qualitative, semi-structured interviews were conducted with 13 practising GPs from 11 practices in the south-west of England, recruited at three GP training events and by sending a flyer to practices. A qualitative approach was deemed most suitable, as this research needed to be conducted with stakeholders going through the process of sickness certification. Participants were sent information packs a week before interview. Participant queries were discussed, and informed consent was given prior to interview.

Saturation sampling was used, in which new interviews are conducted until no new themes emerge from sequential data analysis. $^{27}$

Semi-structured face-to-face interviews were conducted to enable participants to raise novel issues that were salient to their experiences and to generate rich and indepth data. ${ }^{28}$ The interview schedule covered the following topics: GPs' views on the fit note, and on sickness certification for chronic pain conditions, and whether these themes interact.

Interviews were conducted in the participants' workplaces from April to October 2010: following introduction of the fit note. These were audio recorded, transcribed, and coded. Grounded theory principles were used to analyse the data. ${ }^{29,30}$ One researcher used open coding to generate potential codes, accompanied by verbatim quotations. These codes were explored and organised into analytical hierarchies, until core categories were established. Core categories included 'Is there anything particular about chronic pain in relation to sickness certification?; 'Effects of fit note design on consultations'; 'GP-patient relationships and the fit note'; 'Sick role and social capacity'; and 'GPs' relationship to government'.

A second researcher took a selection of the quotations and categorised them into the previously identified core concepts. Differences in interpretation were discussed until consensus was reached. NVivo 8 software was used to organise the analysis.

\section{RESULTS}

The 13 GPs had been practising for a median of 19 years. Four had specialist occupational health qualifications, and 10 were male.

The numbers of people who contributed to each theme are not always shown, as this suggests a representativeness that ignores how themes' strengths were also expressed by degrees of assertion and fervour. 31,32 $^{1,3}$

The results focus on two novel areas: (1) the rationale behind the fit note was judged to be excellent and may help patients with chronic pain to return to work earlier; (2) many barriers to successful fit note use were identified: the need to preserve doctor-patient relationships; inconsistent engagement from employers; GPs' lack of specialist occupational health knowledge; issues with fit note training; and whether a new form can achieve cultural shift.

\section{The rationale behind the fit note is sound and may help patients with chronic pain to return to work earlier}

All participants expressed that if physical risk factors are controlled, work is beneficial to health and that patients do not have to be $100 \%$ fit in order to work:

'Well, I don't think any doctor would disagree that work is good, would they? (GP1) 
and the great majority liked:

'The positive spin on the fit note as they're looking to see what patients can do rather than what they can't and that is a really positive message.' (GP8)

Most said that the fit note would help them to focus the consultation on capacity not incapacity, and that this would be particularly useful in cases where they believed the patient should be returning to work and were meeting resistance. Patients with chronic pain were identified by over half of GPs as being likely to belong to such a group:

'They are stuck in victimhood, often for very good reasons.' (GP10)

Chronic pain patients are a particularly difficult group because, we all have certain preconceptions about them, which may be at times unfair, but they do, unfortunately, often follow a kind of stereotypical presentation. I'm sorry, I'm generalising and it's not fair but generally speaking they are a certain type of patient and they are quite difficult to manage. This note might help with that because it makes us focus on what they can do, not what they can't.' (GP3)

GPs were very aware of the need to negotiate with patients who may not want to return to work. Only one GP was willing to refuse to sign someone off if directly asked, although all GPs had negotiation strategies. These included issuing notes for shorter periods each time, actively engaging patients in target setting, and contacting employers by letter as well as via fit notes to try to get specific support for patients (the latter had not been well responded to). These tactics were summarised by GP 11:

'It's a sort of negotiation, isn't it, you need a lever, and then what you can offer to somebody is being signed off, at least initially. What they can offer back is listening, and being willing to think afresh.'

The majority of GPs believed that the fit note might help negotiate return to work because of the extra space that the form provides, combined with the four options, encouraged more in-depth thought about what would help patients get back to work:

'They do allow us to make more nuanced comments. The boxes are a useful reminder of the things we can say, so instead of just writing "Phased return to work", which I might have written anyway on the old Med 3, as "Phased return to work" is already written out for me, I have found I am expanding my words and putting in more detail and saying things like "Phased return to work, needs to start with coming in from 10am to 3pm 5 days a week for the first 2 weeks".' (GP10)

A minority of GPs were able to give concrete examples of how the fit note might promote return to work:

'The most recent one was a legal secretary who has painful wrists, repetitive strain type injury, so I was able to say I thought she could go back with perhaps reduced hours and not to do the filing, which was particularly heavy on her wrists. Hopefully she's back at work sooner than she might be otherwise and rehabbing.' (GP13)

However, some were unenthusiastic, as they believed that they had always used the Med 3 to make return-to-work suggestions:

'I think it's good in some respects because it gets you thinking, but to be honest, most of us think like that anyway, and most of us are trying to encourage a return to work.' (GP8)

'They've not really changed my practice as I was using the old Med 3 comments box anyway, and writing about phased returns. (GP5)

\section{Barriers to successful fit note use}

The need to preserve doctor-patient relationships. The change from sick to fit note had made no overt difference to what any of the study participants believed about preserving the doctor-patient relationship:

I think the fit note system, the return-towork negotiations, should be patient/employer-led, rather than the doctor, because we are very precious about the doctor-patient relationship. I mean, you can push gently, but if someone says "No, definitely not", you know, I haven't the courage to then have an argument with somebody.' (GP7)

Inconsistent engagement from employers. GPs reported mixed responses from employers, summed up by GP8's comments that:

Sometimes you get very, very supportive employers and sometimes you get completely unsupportive employers who don't understand the processes at all. 
A minority of GPs believed that employers are usually deficient in their responses to the fit note:

I think I understand what it's about but I don't think employers do ... this rules is rules business, HR [human resources] say you are not allowed to come back unless you are $100 \%$ fit, we have this discussion a lot when I am trying to get people back to work to do something.' (GP6)

Six GPs commented that a positive aspect of the fit note is that:

'It puts the onus on the employer'. (GP6)

and:

It might send a message to employers concerning their duty of care to their employees.' (GP11)

Most GPs recognised that employers might not always respond to amended duties', as these options might simply be unavailable, especially within small organisations. This left some GPs feeling that completing the fit note was:

Just a waste of time, unless the actual duties are there.' (GP8)

GPs' lack of specialist occupational health knowledge. The majority of GPs believed that:

'The trouble is, of course, as a GP, I don't necessarily know much about their work. (GP6)

Even those GPs trained in occupational health $(\mathrm{OH})$ felt that there are too many competing angles within a sicknesscertification consultation for such consultations to be effective, and that the fit note does not help this:

'The government's asking GPS, who have no $\mathrm{OH}$ training and who have no knowledge of the person's workplace, to make judgements about occupational fitness and I'm not sure that we're necessarily the best people for that. We should be the patient's advocate not the occupational health's advocate. We're not really qualified and we don't know enough about the job and we've got 10-minute appointments. Occupational health really needs longer than that and, you know, you're dealing with important issues here; you're dealing with people's livelihoods, sick pay, and all the rest of it. So, although I can see the rationale behind it and I can understand that, I think, we've been put in a slightly difficult position here and we haven't got a choice.' (GP8)

The large majority of GPs believed that short consultations impede proper use of the fit note, as there isn't time to investigate fully the patient's job or to engage in useful negotiation:

And the fit note's ideas are great, but we haven't got the time really. And patients often have great difficulty describing what their job is. And it becomes a very generalised discussion really.' (GP9)

Issues with fit note training. A majority of GPs said they simply had no time to read the 18-page DWP training document that was emailed to every practice, ${ }^{23}$ and some were resentful:

II hadn't got time to do that ... we're just bombarded with things to do all the time. (GP1)

'We're cross, a lot of us are cross about all the new things we have to do. This is a tiny part of what we have to do.' (GP10)

No GPs were aware of additional online resources available to them, such as DWP leaflets for GPs and patients, and topic headings for GPs to use within consultations. ${ }^{33}$ When researchers offered copies of these resources, nine GPs were pleased to accept:

'These are very helpful, because actually sickness certification is a tricky thing. '(GP8)

The other four GPs said they had no time to look at these resources. Only three GPs were aware of the work, health, and wellbeing' training sessions on offer from the RCGP, which include the fit note. One had attended a training session, and was extremely positive about it. However, the majority of GPs, when told about this training, felt that it competed with other important events, and that they could not spare additional time away from their surgeries. Some suggested that a solution would be to provide online interactive training that could be undertaken from any computer at any time, others that the government should incentivise GPs to attend the current training, paying them to go, and attaching double continuing professional development (CPD) points to attendance. 
Can a new form achieve cultural shift? It was thought that the fit note only partially addresses very complex issues, and cannot change sickness certification on its own. The majority concurred with GP2:

We need some kind of more fundamental cultural shift, GPS, employers, employees, the whole system.

GP11 also expressed a majority view that:

'It's very challenging to write something that is true, helpful to the person, and to the employer, now that is a tall order ... the commonest tangible thing for all patients, including chronic pain ones, is difficult relationships at work. And I'm not sure that any of this fit note stuff captures that. This isn't going to change the world but it might create an opportunity, it might nudge the system into behaving differently, but it's hearts and minds that need to be won really, not redesigns of bits of paper.

The majority of GPs also said that they would be blamed if sick-listing rates do not reduce, and that this is unfair as it does not take into consideration factors that influence whether or not a patient returns to work, such as other support on offer and whether work itself exacerbates poor health:

We are being made to do the government's work for them for nothing. And that's the message that comes across. Loud and clear. And it'll be our fault if we can't change how we handle our patients. But what if there are no good jobs for them, and it takes ages to get referrals through [to specialist pain or rehabilitation services]?' (GP4)

I mean most of the time I think work is therapeutic - it's better to get back to work and be normal. But for some people, work is the issue, so then I write them a sick note.' (GP12)

Seven doctors said that their role is overemphasised:

'The patient's agenda is key, you know, I don't think that we, as medical people, have as much influence on where the agenda goes as the government may think.' (GP7)

\section{DISCUSSION}

\section{Summary}

Much ambivalence was expressed towards the fit note. A majority of GPs applauded the extra space and tick-box options, as they felt this would lead to more nuanced thinking on their part, which would improve the returnto-work process. Yet a minority of GPs felt that the fit note was redundant, as they had always used the sick note to suggest returnto-work modifications. Also, a majority of GPs felt that the fit note might improve return-to-work negotiations with patients with chronic pain, who were viewed as intransigent. Yet the majority simultaneously felt that the fit note does not acknowledge the particular nature of the doctor-patient relationship and how the GP must be the patient's advocate, keeping interpersonal trust to the fore, which makes it difficult to challenge patients who clearly wish to remain signed off.

GPs had experienced mixed responses from employers, which made them frustrated with the impetus behind the fit note; they believed that reasonable jobs or workplace modifications should be more available to patients, to avoid the workplace exacerbating conditions. Many GPs were concerned about the structural constraints of sickness-certification consultations, such as short time limits and GP' lack of specialist occupational health knowledge, and did not feel the change from sick to fit note had helped these issues. Most GPs were annoyed that the fit note system is a tiny part of their work as generalists and that they need online training that they could do in small blocks of free time.

A common view was that simply introducing the fit note would not achieve the cultural shift away from sick-listing that GPs thought it was designed to accomplish. Some thought that they would be unfairly blamed for this failure. These findings have been disseminated to all participants, and contacts in the NHS, DWP, and Department of Health.

\section{Strengths and limitations}

The semi-structured interviews allowed indepth exploration of complex issues. The authors acknowledge that the purposive sampling strategy probably influenced the findings. Participants were not reimbursed for lost time; GPs stated that they participated because they were interested in chronic pain, and/or return-to-work issues. These GPs may have been more aware of issues to do with sick-listing for patients with chronic pain than would have been the case with stratified or random samples. However, participants gave freely of their time, so were engaged in the interview process, providing detailed responses and commitment to the research. These findings arise from a small sample of 
south-west GPs in populations experiencing relatively low levels of unemployment and illness-related work absences compared to other areas of the UK. GPs working with different populations need to be examined. Peer audit was used to enable replication and to ensure credibility, ${ }^{34}$ as an experienced health-services researcher checked the primary researcher's initial coding. This research specifically focused on chronic pain conditions, but many of the findings may be transferable to patients with other chronic and non-specific health complaints. ${ }^{14-16,24}$

\section{Comparison with existing literature}

There is very little research on the UK fit note. The sample fit note was compared to Med 3s using vignettes, and researchers found GPs considered significantly higher proportions of patients fit for some work rather than none, under the new system. ${ }^{35}$ The findings of the present study suggest that GPs think the fit note can assist in actual consultations, although they have reservations. They also support the view that although GPs are worried about the lack of training on the sick note, they do have core communication, clinical, and negotiating skills from their general experience, and are capable of using these skills to get more patients back to work. ${ }^{36}$

The literature on partial return to work in Scandinavia (for example, via amended hours and phased returns) was reviewed. Researchers found that communication between stakeholders was poor, so it was difficult to increase its uptake. ${ }^{37}$ The findings of this study concur.

GPs in the present study wanted more interactive online training. It is known that GPs get very little formal training in sickness certification; ${ }^{9,12}$ research has suggested that more should be provided, though GPs also learn how to assess sick leave via clinical practice. ${ }^{38}$

\section{Implications for research and practice}

GPs believed that there were many external factors that make sickness-certification consultations difficult, such as inconsistent employer engagement with the fit note. The current research group is interviewing employers to establish their views on the fit note, and on interactions with sick-listed workers and GPs; there is a need to know more about how all three sets of stakeholders are using the fit note and how it might be used to improve communication between them.

There is now online training of the kind GPs in this study wanted; research is needed to assess its take-up rate and effectiveness in helping GPs manage the fit note system.

It would be useful to interview GPs and patients with chronic pain before and after observing their sickness-certification consultations, in order to compare GP and patient views on sickness certification with what happens in practice. This has been fruitfully studied in other areas of general practice. ${ }^{39}$ 


\section{REFERENCES}

1. Waddell G, Burton K. Concepts of rehabilitation for the management of common health problems. London: The Stationery Office, 2004.

2. Parsons T. The social system. New York: Free Press, 1951.

3. Hiscock J, Ritchie J. The role of GPs in sickness certification. London: Department for Work and Pensions, 2001.

4. Hussey $S$, Hoddinott P, Wilson P, et al. Sickness certification system in the United Kingdom: qualitative study of views of general practitioners in Scotland. BMJ 2004; 328(7431): 88 .

5. Verbeek J, Sengers MJ, Riemens L, Haafkens J. Patient expectations of treatment for back pain: a systematic review of qualitative and quantitative studies. Spine 2004; 29(20): 2309-2318.

6. Wahlstrom R, Alexanderson K. Physicians' sick-listing practices. In: Swedish Council on Technology Assessment in Health Care. Sickness absence: causes, consequences, and physicians' certification practice. A systematic literature review by the Swedish Council on Technology Assessment in Health Care. Scand J Public Health 2004; 63: 222-255.

7. Arrelöv B, Alexanderson K, Hagberg J, et al. Dealing with sickness certification - a survey of problems and strategies among general practitioners and orthopaedic surgeons. BMC Public Health 2007; 7: 273.

8. Shiels C, Gabbay MB. Patient, clinician, and general practice factors in long-term certified sickness. Scand J Public Health 2007; 35(3): 250-256.

9. Roope R, Parker G, Turner S. General practitioners' use of sickness certificates. Occup Med 2009; 59(8): 580-585.

10. Money A, Hussey L, Thorley K, et al. Work-related sickness absence negotiations: GPs' qualitative perspectives. Br J Gen Pract 2010; 60(579): 721-728.

11. Wynne-Jones G, Mallen CD, Main CJ, Dunn KM. What do GPs feel about sickness certification? A systematic search and narrative review. Scand J Prim Health Care 2010; 28(2): 67-75.

12. Wynne-Jones G, Mallen CD, Main CJ, Dunn KM. Sickness certification and the GP: what really happens in practice? Fam Pract 2010; 27(3): 344-350.

13. Waddell G, Aylward M. The scientific and conceptual basis of incapacity benefits. London: The Stationery Office, 2005.

14. Wessely S, Nimnuan C, Sharpe M. Functional somatic syndromes: one or many? Lancet 1999; 354(9182): 936-939.

15. Halligan P, Bass C, Oakley D (eds). Malingering and illness deception. Oxford: Oxford University Press, 2003.

16. Wainwright D, Calnan M, O'Neil C, et al. When pain in the arm is 'all in the head': the management of medically unexplained suffering in primary care. Health Risk Soc 2006; 8(1): 43-58.

17. Black C. Working for a healthier tomorrow; Dame Carol Black's review of the health of Britain's working age population. London: The Stationery Office, 2008.

18. Arrelöv B, Borgquist L, Ljungberg D, Svardsudd K. The influence of change of legislation concerning sickness absence on physicians' performance as certifiers: A population-based study. Health Policy 2003; 63(3): 259-268.

19. Meershoek A, Krumeich A, Vos R. Judging without criteria? Sickness certification in Dutch disability schemes. Sociol Health Illn 2007; 29(4): 497-514.
20. Freud D. Reducing dependency, increasing opportunity: options for the future of welfare to work. London: Department for Work and Pensions, 2007.

21. Waddell G, Burton K. Is work good for your health and wellbeing? London: The Stationery Office, 2006

22. Department of Work and Pensions. Sick note to fit note - helping people to stay in work. http://www.dwp.gov.uk/fitnote/ (accessed 2 Aug 2011).

23. Department of Work and Pensions. Statement of fitness for work - a guide for GPs and other doctors. London: DWP, 2010. http://www.dwp.gov.uk/docs/fitnotegp-guide.pdf (accessed 2 Aug 2011).

24. Watson PJ, Bowey J, Purcell-Jones G, Gales T. General practitioner sickness absence certification for low back pain is not directly associated with beliefs about back pain. Eur J Pain 2008; 12(3): 314-320.

25. Coole C, Watson PJ, Drummond A. Work problems due to low back pain: what do GPs do? A questionnaire survey. Fam Pract 2010; 27(1): 31-37.

26. Coole C, Watson PJ, Drummond A. Staying at work with back pain: patients' experiences of work-related help received from GPs and other clinicians. A qualitative study. BMC Musculoskelet Disord 2010; 11: 190

27. Guest G, Bunce A, Johnson L. How many interviews are enough? An experiment with data saturation and variability. Field Methods 2006; 18(1): 59-82.

28. Denzin NK, Lincoln YS (eds). Handbook of qualitative research. Thousand Oaks, CA: Sage, 1994

29. Glaser BG, Strauss AL. The discovery of grounded theory; strategies for qualitative research. Chicago, IL: Aldine, 1967.

30. Green J, Thorogood N. Qualitative methods for health research. London: Sage, 2004

31. Gabe J, Bury M, Ramsay R. Living with asthma: the experiences of young people at home and at school. Soc Sci Med 2002; 55(9): 1619-1633.

32. Wenger GC. Old people's health and experiences of the caring services. The institute of human ageing. Occasional Paper. Liverpool: Liverpool University Press, 1988

33. Advising patients about work. An evidence-based approach for general practitioners and other healthcare professionals. London: The Stationery Office, 2007. http://www.dwp.gov.uk/docs/hwwb-health-work-gp-leaflet.pdf laccessed 2 Aug 2011).

34. Chapple A, Rogers A. Explicit guidelines for qualitative research: a step in the right direction, a defence of the 'soft' option, or a form of sociological imperialism? Fam Pract 1998; 15(6): 556-561.

35. Sallis A, Birkin R, Munir F. Working towards a fit note: an experimental vignette study. Br J Gen Pract 2010; 60(573): 245-250.

36. Gabbay M. Electronic fit notes: sickness certification in the new decade. $\mathrm{Br} J$ Gen Pract 2010; 60(573): 235-236

37. Kausto J, Miranda H, Martimo KP, Viikari-Juntura E. Partial sick leave - review of its use, effects and feasibility in the Nordic countries. Scand J Work Environ Health 2008; 34(4): 239-249.

38. Lofgren A, Silen C, Alexanderson K. How physicians have learned to handle sickness-certification cases. Scand J Public Health 2011; 39(3): 245-254.

39. Barry CA, Bradley CP, Britten N, et al. Patients' unvoiced agendas in general practice consultations: qualitative study. BMJ 2003; 320(7244): 1246-1250. 